\title{
Patient Safety in Blogs and Wikis Entries by Patients and For Patients
}

\section{Jose Joaquin Mira ${ }^{1-3 *}$, Isabel Maria Navarro ${ }^{2}$ and Roberto Nuño ${ }^{4}$}

${ }^{1}$ Sant Joan-Alacant Health District, Consellería Sanitat, Alicante, Spain

${ }^{2}$ Miguel Hernández University, Elche, Spain

${ }^{3}$ Research Network on Health Services in Chronic Diseases (REDISSEC), Spain

${ }^{4}$ Basque Institute for Healthcare Innovation (O+berri), Bilbao, Spain

\begin{abstract}
Background: Many patients changed their behaviour because of the Internet. The influence of virtual communities is on the increase.

Objective: The aim of this study was to examine whether virtual communities for patients provide information that facilitates safer use of medication.

Methods: Observational study of websites with information about the safe use of those medicines most widely prescribed for the illnesses most prevalent in Spain. Three types of information providers were considered: housing independent virtual communities or networks for patients (IW); healthcare institutions or patients' associations (HP); and pharmaceuticals industry $(\mathrm{PI})$. Ten items of information about a safer use of medication were defined. One point was assigned when information was provided (maximum score 10 points). Cohen's Kappa was used to determine the level of agreement between the reviewed Websites.

Results: A total of 1342 websites were identified, which were reduced to 153 (14 classed as PI sites, 77 as IW and 15 as HP). Overall level of agreement between assessors was $0.93(p<0.001)$. The overall score was 3 points (SD 1.8), with no significant differences between the scores for the three providers $(p=0.146)$. Scores ranged from a mean of 2.8 (SD 1.7) points in the case of IW, 3.0 (SD 1.7) PI, and 3.8 (SD 2.2) HP. Information about dosage, storage, recommendations for avoiding medication errors and information about what to do in cases of adverse events were more difficult to find. None of the sites provided patients with a system for reporting/registering adverse events.

Conclusion: Virtual communities do not offer information for helping patients to avoid errors or improve their treatment adherence based on the experience of patients. This information is very similar to that already offered other websites. The credibility of health and medical information available in the growing number of virtual communities should be to assess.
\end{abstract}

Keywords: e-health; e-patient; Internet; Health education; Patient safety

\section{Introduction}

Internet contributes to patients' independence and facilitates selfcare [1]. In Spain, according to recent data, up to $61 \%$ of patients turn to Internet to seek information on health-related issues [2]. A total of 53\% stated that they changed their behaviour because of the information they found on the Web. E-patients go to Internet for various reasons, including: to find information about illnesses and disease, to share their experiences with other patients or with professionals, or to seek information about new/alternative therapies.

The influence of virtual communities is on the increase, and patients are accessing such communities [3] (blogs, discussion groups of forums, news groups, wikis, etc.) more and more, with a view to exchanging information on how to deal with their illness on a day-today basis and to seeking advice about the correct use of medication and any precautions they should take. It is well known that patients are subject to errors (of omission and commission) with medication [4], and use a range of strategies (pillboxes, notes on medicine packaging, associating taking medicines with meals, etc.) to reduce such errors and improve their treatment adherence $[5,6]$. The information on safe use of medicines provided by these virtual communities has begun to be studied [7], though that electronic word-of-mouth (eWOM) communication shares the problems of reliability and credibility found on analyzing health information websites $[8,9]$.

The aim of the present study was to determine whether virtual communities for patients set up by healthcare institutions, patients' associations and independent organizations provide information that facilitates safer use of medication.

\section{Materials and Methods}

Observational study in which the authors consulted websites with information about the safe use of those medicines most widely prescribed for the illnesses most prevalent in Spain. Three types of information providers were considered: first, websites housing independent virtual communities or networks for patients (IW); second, portals representing healthcare institutions or patients' associations and in which there is active participation from health professionals (HP); and third, pharmaceuticals industry websites (PI).

The most prevalent illnesses or conditions were identified on the basis of morbidity data from the Spanish Health Survey for 2011/12, and were as follows: high blood pressure, COPD (chronic obstructive pulmonary disease), asthma, diabetes, arthrosis, back pain, varicose

${ }^{*}$ Corresponding author: Jose Joaquin Mira, Avda de la Universidad, s/n, 03202, Elche Altamira Building, Spain, Tel: 966658984; E-mail: jose.mira@umh.es

Received May 16, 2014; Accepted November 13, 2014; Published November 17,2014

Citation: Mira JJ, Navarro IM, Nuño R (2014) Patient Safety in Blogs and Wikis Entries by Patients and For Patients. J Health Med Informat 5: 172. doi:10.4172/2157-7420.1000172

Copyright: (c) 2014 Mira JJ, et al. This is an open-access article distributed under the terms of the Creative Commons Attribution License, which permits unrestricted use, distribution, and reproduction in any medium, provided the original author and source are credited. 
veins in the legs, peptic ulcer and depression. The most commonly prescribed medicines were identified from the Madrid Health Service's prescription management program $\left(\right.$ Farmadrid $\left.^{\star}\right)$, based on the number of packages dispensed throughout 2010 for the treatment of these conditions.

The search engine used was Google. Key words used for locating portals and sites were: patients' forums, patients' social networks, patients' virtual communities, patient communities, patients' webs, online patients' groups, network groups for patients, virtual schools for patients, web schools for patients, and patients' associations. In addition to the use of key words, a specific indicator was used for each of the most prevalent illnesses identified, so that the researchers selected the first 20 results (websites) provided by the search engine for each one of the descriptors. Once the websites had been located, they were screened by three trained assessors (IN, AL and IC), who discarded results involving broken links, news items, document downloads, Wikipedia articles, scientific journals, special issues of journals, portals not addressing patients, purely informational sites provided by public authorities, YouTube videos, commercial portals, or websites that directed the search to the same portal. Additionally, it was assessed whether the website provided information on the use of medication and whether it offered open and public spaces in which patients could exchange opinions or information, make recommendations, ask questions and resolve doubts. Subsequently, and independently, the three assessors browsed through the portal to identify and codify the information provided in relation to the safe use of medication. Once the website had been located, the browsing process involved following all the links found. All the pages to which the links led were at least checked by the researchers for relevant information.

The coding of information for each one of the most prevalent health conditions took into account whether the website offered comprehensive information on: treatment and medication; alternative medication and treatment; possible side-effects and precautions to bear in mind with the different treatments and medication; possible interactions for patients taking more than one medicine; dosage, frequency and length of treatment; recommendations concerning timetabling, taking the medicine with food/without food, and physical activity; storage of the medication; recommendations for avoiding the most common medication errors by patients; and finally, information about what to do, where to go and/or whom to contact in case of an adverse event. The coding process also took into account whether the website provided an actual telephone number to call in case of an adverse event and/or a system for reporting/registering adverse events. These criteria were established by the researchers through consensus. For each one of the criteria the assessors assigned 1 point when the information in question was provided, and 0 when it was not. Score on the total scale ranged from 0 to 10 points, that is, 1 point for each criterion for which information was made available.

To determine the level of agreement between assessors we used Cohen's Kappa, considering there to be a high degree of agreement when the statistical value was higher than 0.81 .

Once the level of agreement between assessors had been established, we first counted the number of websites that provided information in relation to the criteria of interest. Secondly, we calculated a total score on the scale for each of the websites analyzed. For each of the criteria we assigned 1 point when the criterion was met and 0 when it was not. In order to identify differences between the various providers of information, we carried out a non-parametric test for independent samples and used the Kruskal-Wallis statistic for comparing the scale scores and the chi-squared test for analyzing the relations between qualitative variables.

\section{Results}

By means of the Google search a total of 1342 websites were identified, which were reduced to 153 on discarding those that redirected the search to the same portal, those involving broken links, news items, document downloads, Wikipedia articles, scientific journals, special issues of journals or YouTube videos, and portals not addressing patients, static informational sites and commercial portals. On assessing whether the website provided information on the use of medication and whether it provided open and public spaces in which patients could exchange opinions or information, make recommendations, ask questions and resolve doubts, 47 websites were discarded as candidates for the codification of information. The information for a total of 106 sites was eventually coded, 14 of which could be classed as pharmaceuticals industry sites, 77 as sites housing virtual communities or networks not linked to healthcare institutions, and 15 as sites associated with some public health institution. In these last cases, 7 of the 15 sites involved the participation of healthcare professionals, 3 of them referred to virtual patients' schools endorsed by public healthcare authorities, and 5 were run by patients' associations. Overall level of agreement between assessors was $0.93(p<0.001)$, and ranged from $0.87(\mathrm{p}<0.001)$ in the case of sites promoted by healthcare institutions or patients' associations (HP), $0.92(\mathrm{p}<0.001)$ in that of pharmaceuticals industry sites $(\mathrm{PI})$, and $0.93(\mathrm{p}<0.001)$ for independent websites (IW).

The overall score was 3 points (SD 1.8), with no significant differences between the scores for the three different types of website provider $(\mathrm{p}=0.146)$. Scores ranged from a mean of 2.8 (SD 1.7) points in the case of IW, 3.0 (SD 1.7) points in that of PI, and 3.8 (SD 2.2) points in that of HP. On analyzing the information related to each one of the criteria (Table 1), we found that it was easy for e-patients to find descriptive information on the characteristics of the treatment of choice, on alternative treatments, on the most common side effects and on precautions (e.g., related to possible interactions). On the other hand, it was more difficult for them to find clear information about dosage, storage, recommendations for avoiding medication errors and information about what to do in cases of adverse events. Practically none of the sites provided patients with a system for reporting/ registering adverse events. On comparing the scores assigned, no statistically significant differences were found between the three groups of websites (Table 1).

\section{Discussion}

Virtual communities do not offer any information over and above that offered by other websites for helping patients to avoid errors or improve their treatment adherence, even though the sharing of patients' experiences. The information made available to patients about the most common treatments for the most prevalent illnesses or conditions is basically the same as that which can be found in the patient information leaflets that come with medicines.

Although there are an increasing number of studies on eWOM (3) the number of studies analysing the contribution of virtual communities to patient safety is scarcely. In the light of these results the Spanish websites endorsed by healthcare institutions and patients' associations offer more comprehensive information, should they be the recommended over independent virtual communities.

The first studies on the health Internet information put highlighted 
Citation: Mira JJ, Navarro IM, Nuño R (2014) Patient Safety in Blogs and Wikis Entries by Patients and For Patients. J Health Med Informat 5: 172. doi:10.4172/2157-7420.1000172

Page 3 of 3

\begin{tabular}{|c|c|c|c|c|c|}
\hline & \multicolumn{4}{|c|}{ Provider $^{\star}$} & \multirow[t]{2}{*}{ Total } \\
\hline & HP & $\mathrm{PI}$ & IW & $p=$ & \\
\hline Treatment of choice & $11(73.3)$ & $10(71.4)$ & $62(80.5)$ & 0.49 & $83(78.3)$ \\
\hline Alternative treatment & $11(73.3)$ & $6(42.9)$ & $39(50.6)$ & 0.09 & $56(52.8)$ \\
\hline Side effects and precautions & $11(73.3)$ & $6(42.8)$ & $42(54.5)$ & 0.10 & $59(55.7)$ \\
\hline Medication interactions & $11(73.3)$ & $5(35.7)$ & $22(28.6)$ & 0.002 & $32(30.2)$ \\
\hline Dosage & $5(33.3)$ & $4(28.6)$ & $22(28.6)$ & 0.84 & $30(28.3)$ \\
\hline Recommendations for avoiding medication errors & $4(26.7)$ & $2(14.3)$ & $10(13.0)$ & 0.32 & $18(17.0)$ \\
\hline Indications in case of $\mathrm{AE}$ & $6(40.0)$ & $3(21.4)$ & $12(15.6)$ & 0.06 & $20(18.9)$ \\
\hline Storage of medication & $5(33.3)$ & $4(28.6)$ & $1(1.3)$ & $<0.001$ & $6(5.7)$ \\
\hline Contact in case of $\mathrm{AE}$ & $1(6.7)$ & $2(14.3)$ & $3(3.9)$ & 0.34 & $6(5.7)$ \\
\hline System for reporting $\mathrm{AE}$ & $2(13.3)$ & $0(0.0)$ & $2(2.6)$ & 0.08 & $4(3.8)$ \\
\hline Total websites analysed & 14 & 15 & 77 & & \\
\hline
\end{tabular}

Data represent the total number of websites that contain relevant information; in brackets, percentage of the total of sites and portals analyzed.

Statistic applied was chi-squared.

$A E=$ Adverse effects

* HP: Health portals-with participation of healthcare institutions or endorsed/run by patients' associations; PI: Pharmaceuticals industry websites; IW: Websites housing independent virtual communities or networks for patients.

Table 1: What information about medication can be found according to the type of information provider.

gaps in the reliability of that information [8]. However the quality of the information on the Internet improved in a very short time [10]. It is likely that gradually the same phenomenon occurs and these virtual communities assume the responsibility of introducing improvements in the quality of the information. The virtual communities information should be directed to collect the experience of patients. They could contribute resolving the gaps related to managing medication at home and reducing the most common patient medication errors.

These results justify an emphasis in this research field on the need to critically assess the credibility of the health information available $[9,10]$. Virtual communities should be expected to have greater credibility [11] hence they have a potential effect on the patients' behaviour. Including patient safety focus should reduce risks related to medication.

\section{Limitations}

We did not assess the intrinsic quality of the information or its understandability (legibility study). Furthermore, given the dynamic nature of the Internet, the situation found in the present study could become quite different in the relatively short term.

\section{Acknowledgement}

Ana López (AL) and Irene Carrillo (IC) assisted searching and assessing websites. This study was funded by the Health Research Fund (Fondo de Investigación Sanitaria), reference PI10/01344.

\section{References}

1. Rong-Huang Q (2003) Creating informed consumers and achieving shared decisions making. Aust Fam Physician 32: 335-341.

2. Marin-Torres V, Valverde J, Sánchez I, Sáenz del Castillo MI, PolentinosCastro E, et al. (2013) Internet como fuente de información sobre salud en pacientes de atención primaria y su influencia en la relación médico-paciente. Aten Primaria 45: 46-53.

3. Chih WH, Wang KY, Hsu LC, Huang SC (2013) Investigating Electronic Wordof-Mouth Effects on Online Discussion Forums: The Role of Perceived Positive Electronic Word-of-Mouth Review Credibility. Cyberpsychol Behav Soc Netw 16: $658-668$

4. Mira JJ, Navarro IM, Guilabert M, Aranaz J (2012) Frecuencia de errores de los pacientes con su medicación. Rev Panam Salud Publica 31: 95-101.
5. Branin JJ (2001) The role of memory strategies in medication adherence among the elderly. Home Health Care Serv Q 20: 1-16.

6. Mira JJ, Orozco-Beltrán D, Pérez-Jover V, Martinez-Jimeno L, Gil-Guillén V, et al. (2012) Physician patient communication failure facilitates medication errors in older polymedicated patients with multiple comorbidities. Fam Pract 30: 56-63.

7. Emmerton LM, Mampallil L, Kairuz T, McKauge LM, Bush RA (2012) Exploring health literacy competencies in community pharmacy. Health Expect 15: 12-22.

8. Eysenbach G, Powell J, Kuss O, Sa ER (2002) Empirical studies assessing the quality of health information for consumers on the World Wide Web: systematic review. JAMA 287: 2691-2700.

9. Kunst H, Groot D, Latthe P, Khan K (2002) Accuracy of information on apparently credible websites: survey of five common health topics. BMJ 324 581-582.

10. Mira JJ, Llinás G, Pérez-Jover V (2008) Habits of Internet users and usefulness of websites in Spanish for health education. World Hosp Health Serv 44: 30-35

11. Purcarea VL, Gheorghe JR, Petrescu CM (2013) Credibility Elements of eWOM Messages in the Context of Health Care Services. A Romanian Perspective J Med Life 6: 254-259. 